\title{
Ultra-Wideband Log Periodic Dipole Antenna (LPDA) for Wireless Communication Applications
}

\author{
Dalia N. Elsheakh, Esmat A. Abdallah \\ Microstrip Department, Electronics Research Institute, El Dokki, Egypt \\ Email: daliaelsheakh@eri.sci.eg
}

How to cite this paper: Elsheakh, D.N. and Abdallah, E.A. (2018) Ultra-Wideband Log Periodic Dipole Antenna (LPDA) for Wireless Communication Applications. Journal of Electromagnetic Analysis and Applications, 10, 119-129.

https://doi.org/10.4236/jemaa.2018.106009

Received: April 26, 2018

Accepted: June 26, 2018

Published: June 29, 2018

Copyright (c) 2018 by authors and Scientific Research Publishing Inc. This work is licensed under the Creative Commons Attribution International License (CC BY 4.0).

http://creativecommons.org/licenses/by/4.0/

\begin{abstract}
This paper proposes a printed log-periodic dipole antenna (LPDA) for ultra wide bandwidth (UWB) applications. The antenna comprises of cascading four $U$ shaped elements of different line lengths with balun circuit to improve the antenna impedance matching. The proposed antenna dimensions are $50 \times$ $50 \mathrm{~mm}^{2}$ with FR4 substrate thickness $0.8 \mathrm{~mm}$. Full-wave EM solver HFSS (High Frequency Structure Simulator) is used for modeling the proposed antenna. The pulse distortion is verified by the measured the proposed antenna performance with virtually steady group delay. The simulation and experimental results show that the proposed antenna exhibits good impedance matching, stable radiation patterns throughout the whole operating frequency bands, acceptable gain and stable group delay over the entire operating band. An UWB extended from $1.85 \mathrm{GHz}$ to $11 \mathrm{GHz}$ is obtained, and the average antenna gain is about $5.5 \mathrm{dBi}$ over the operating band with peak gain around 6.5 $\mathrm{dBi}$ and $70 \%$ average radiation efficiency.
\end{abstract}

\section{Keywords}

High Frequency Structure Simulation (HFSS), Dipole Antenna, Log Periodic, Coplanar Waveguide (CPW), Ultra Wideband (UWB), Radiation Pattern, Radiation Efficiency, Group Delay

\section{Introduction}

Latterly, much progress has been made in ultra-wideband (UWB) applications with high data rate communications in short distances with low fabrication cost. UWB system antennas demand serious challenges to achieve wide impedance bandwidth, compact size, high gain, linear group delay, stable radiation patterns 
[1] [2] [3] [4] and to meet the demand for mobile, wireless communication, personal applications, the industrial medical ISM-band $2.4 \mathrm{GHz}$, LTE $2.1 \mathrm{GHz}$, the IEEE 802.11a bands (5.15 - $5.35 \mathrm{GHz}, 5.725$ - $5.825 \mathrm{GHz}$ ) HIPERLAN/2 bands $(5.15-5.35 \mathrm{GHz}, 5.470-5.725 \mathrm{GHz})$ which can interfere with the UWB communication systems [5] [6]. In addition, FCC in 2002 released the UWB protocol that covers the frequency range from $3.1-10.6 \mathrm{GHz}[1]$. UWB antennas used planar microwave circuitry have generated attractive radiating structures with high gain, low weight, reliability, ease of manufacturing and integration such as the Vivaldi antennas [7] [8], and the tapered slot antenna [9]. The most suitable solution at microwave frequencies appears to be the printed planar log-periodic dipole (LPDA) [5] [6]. LPDAs have a lot of advantages, such as directive radiation pattern, linear polarization and low cross polarization ratio over a wide frequency range [5]. At the beginning, coaxial cable is used for feeding the printed LPDAs at the radio and the TV frequency bands; however, it was found that the performance became worse when frequency increases. LPDA is UWB with the multiple resonance property; its bandwidth can be enhanced by increasing the number of the dipole elements [8] [9] [10] [11]. Balanced structure, CPW fed antennas are very good candidates since the feed lines and the slots are on the same side of the substrate. There are many researches done to design LPDA as shown in Table 1 to resonate at different wireless communications or for UWB applications. Table 1 shows that most of published papers for LPDA are not compact and their size are near from wavelength.

In this paper a new proposed ultra wideband antenna, is presented which consists of a combined structure of different lengths of printed U-shaped LPDA fed by CPW and balun circuit to improve the impedance matching. These bands are used for different wireless communications applications and also for UWB applications. The USLPDA as shown in Figure 1 has been designed with 3D electromagnetic simulation HFSS ver. 14. The compact antenna dimensions are $50 \times 50 \times 0.8 \mathrm{~mm}^{3}$ when printed on a FR4 dielectric substrate. The proposed USLPDA antenna introduces USUWB with the multiple resonant property and compact size compared to earlier designs where ultra wide bandwidth was realized using a rectangular slot [9].

USLPDA bandwidth can be enhanced by increasing the number of the

Table 1. Comparison of proposed antenna with other antennas (all dimensions in $\mathrm{mm}$ ).

\begin{tabular}{ccccc}
\hline Ref. & $L \times W \mathrm{~mm}^{2}$ & Sub. Thickness & Diel. Properties & BW GHz \\
\hline$[6]$ & $91 \times 57$ & 1.578 & $\varepsilon_{r}=2.2, \tan \delta=0.0009$ & $2.75-11$ \\
{$[7]$} & $29 \times 26$ & 1.588 & $\varepsilon_{r}=4, \tan \delta=0.02$ & $1.8-3.75$ \\
{$[8]$} & $45 \times 60$ & 1.5 & $\varepsilon_{r}=4.4, \tan \delta=0.02$ & 5 to 40 \\
{$[9]$} & $70 \times 40$ & 0.51 & $\varepsilon_{r}=2.5, \tan \delta=0.0002$ & 4 to 18 \\
{$[10]$} & $238 \times 112$ & 1.58 & $\varepsilon_{r}=2.2, \tan \delta=0.0001$ & 2 to 18 \\
Our & $50 \times 50$ & 0.8 & $\varepsilon_{r}=4.6, \tan \delta=0.02$ & 1.85 to 11 \\
\hline
\end{tabular}




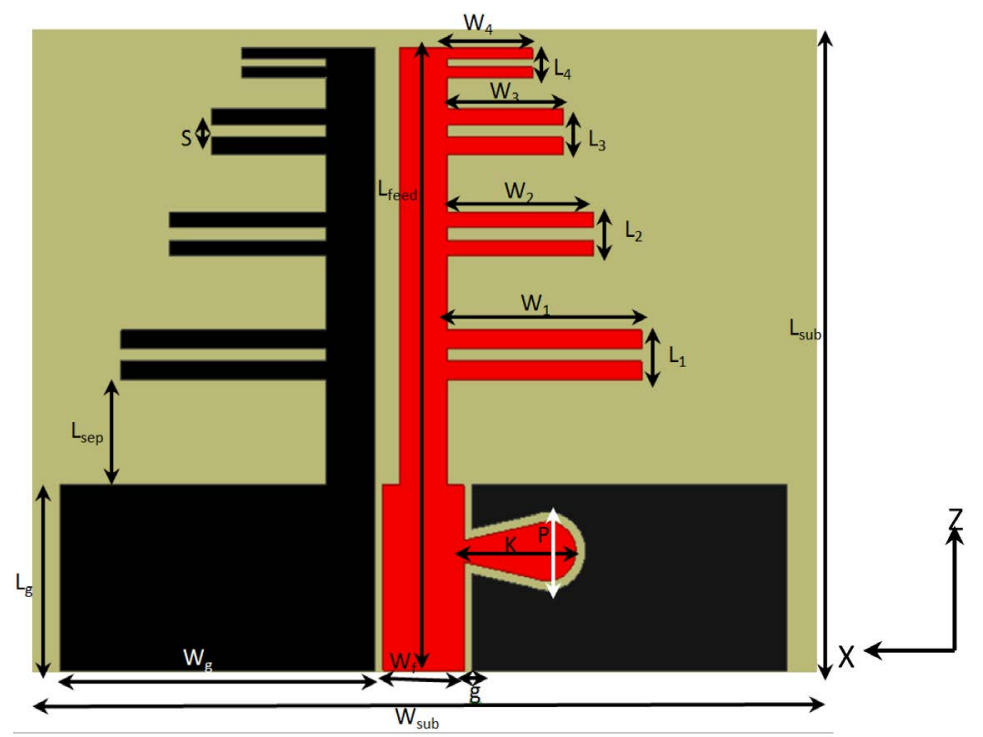

Figure 1. Layout of the proposed log periodic dipole antenna (US-LPDA).

U-shaped dipole elements or stubs [10]-[15]. The $-10 \mathrm{~dB}$ bandwidth of this antenna extends from 1.85 to $11 \mathrm{GHz}$ which is wide enough to cover the FCC approved UWB in addition to wireless communications. The antenna exhibits good performance and can operate at wireless applications. The antenna structure with design, parametric study and the evolution of the proposed the antenna are presented in Section 2. In Section 3, proposed antenna is analyzed in terms of reflection coefficient, surface current distribution, group delay and antenna gain. The fabricated antenna is evaluated based on the measurement of $\left|S_{11}\right|$ and radiation pattern in Section 4. Finally, Section 5 concludes the proposed work.

\section{Antenna Geometry and Design}

The proposed antenna geometry is shown in Figure 1; the antenna consists of four different lengths of LPDA with U-shaped stubs. The lengths and spacing of the elements of a log-periodic antenna increase logarithmically from one end to the other. The design of the LPDA is used where a wide range of frequencies is needed while still having moderate gain and directionality. The initial design is validated and optimized by simulating the proposed antenna using HFSS. The proposed antenna is built on a low-cost FR4 substrate with substrate thickness $0.8 \mathrm{~mm}$, dielectric constant $\varepsilon_{r}=4.6$, and loss tangent $\tan \delta=0.02$ as shown in Figure 1 . The antenna is fed by a $50 \Omega$ transmission line, which can be easily integrated with other microwave circuits printed on the same substrate. For designing procedure, a number of trial steps are needed, the scale-factor $\tau$, spacing factor $\delta$, and the number of the dipole elements $N$ should be determined. Second, the length of the longest arm, which responses to the lowest resonance frequency $f_{l}$, should be computed by following Equations (1) to (6) [1]. The dimensions of the traditional antenna elements can be determined with: 


$$
\begin{gathered}
\frac{W_{i-1}}{W_{i}}=\tau \\
\delta=\frac{L_{\text {isep }}}{4 W_{i}} \\
W_{1}=\frac{\lambda_{1, e f f}}{4} \\
N=1-\left(\ln B_{s} / \ln \tau\right) \\
B_{a}=1.1+30.7 \delta(1-\tau) \\
B_{s}=B_{a} B_{o}
\end{gathered}
$$

where $\lambda_{1, \text { eff }} B_{o}, N$, int $i$ are the longest effective operating wavelength, the operating frequency, number of elements, and $i$ is an integer that varies from 2 to 5 , respectively. The lengths of the first, second, third and fourth dipoles should be scaled due to the effective dielectric constant of antenna substrate. Based on the traditional design procedure, we propose a new USLPDA, in which the scale factor and the spacing factor are different compared to the traditional equations. As shown in Figure 1, by cascading the straight line LPMA, UWB antenna is realized, where the red elements are the radiator surface of the substrate and the black elements are the ground plane surface of the substrate. Four U-shaped stubs are added in each element to add extra four resonant frequencies when their lengths equal to quarter wavelength. To improve the impedance matching the balun circuit with suitable dimensions is used as shown in Figure 2.

\section{Simulated Results}

The antennas are modeled and analyzed by using HFSS electromagnetic software. The simulated $\left|S_{11}\right|$ for the antenna design steps are depicted in Figure 3. However, the overall impedance bandwidth for the proposed U-shaped log periodic dipole model is much wider.

The introduced design started by conventional dipole with length $45 \mathrm{~mm}$ as shown in Figure 2(a) which resonates at $2.4 \mathrm{GHz}$ as shown by dashed black line in Figure 3. The second step of design is adding balun circuit to improve the antenna bandwidth as shown in Figure 2(b) and the corresponding result is shown as solid red line in Figure 3. First US-LPDA is added in the third step of design as shown in Figure 2(c), this adds two extra resonant frequencies as

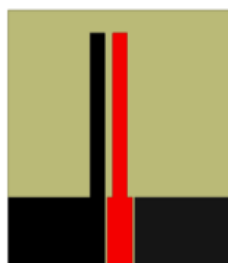

(a)

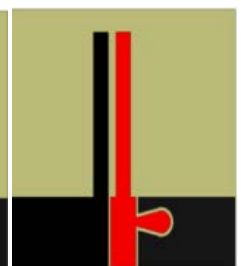

(b)

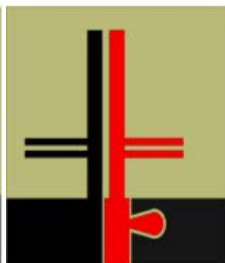

(c)

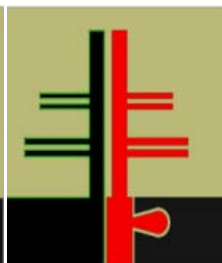

(d)

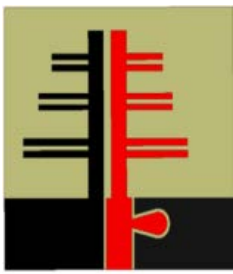

(e)

Figure 2. From (a) to (e) evolution of the design steps of the proposed US-LPDA. 


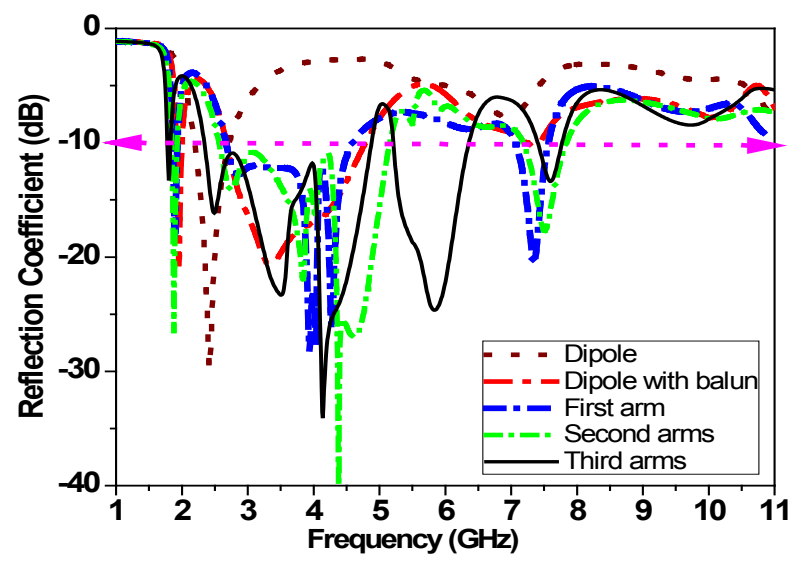

Figure 3. Design procedures of the USLPDA antenna.

shown as blue dashed line in Figure 3. Continuing the design by adding the second U-shaped element, as shown in Figure 2(d), the response is shown as green line in Figure 3. In addition, a third element is added as shown in Figure $2(\mathrm{e})$ and its response is show in Figure 3 as brown dashed line. Final design as shown in Figure 1 and the corresponding $\left|S_{11}\right|$ results are shown in Figure 4. There are two orientations of the elements arrangement with the same lengths either from small size element length to large size element or vice versa as shown in Figure 4(a). The reflection coefficients $\left|S_{11}\right|$ of both orientations are shown in Figure 4(b). The orientation from small to large size elements gives lower antenna resonant frequency at $1.5 \mathrm{GHz}$ with poor impedance matching, while the other orientation from large to small size elements gives resonant frequency at $1.85 \mathrm{GHz}$ and good impedance matching.

The effects of each arms of the proposed antenna are also studied and the simulated reflection coefficient of varied each arm and kept the other arms fixed are shown in Figure 5.

Figure 5 Shows the effect of varies $\mathrm{L}_{1}, \mathrm{~L}_{2}, \mathrm{~L}_{3}$ and $\mathrm{L}_{4}$ and the corresponding results are shown in Figure 5(a) to Figure 5(d). Optimized antenna dimensions are shown in Table 2. Simulated current density distributions of the USLPDA with four elements are shown in Figure 6 at different resonant frequencies take place at $1.85 \mathrm{GHz}, 2.45 \mathrm{GHz}, 3.5 \mathrm{GHz}, 5.5 \mathrm{GHz}, 7.5 \mathrm{GHz}$ and $10 \mathrm{GHz}$. The current distribution of the proposed antenna is studied to verify the operation of the USLPDA. The largest element fundamental resonant frequency of the multi arms is $1.75 \mathrm{GHz}$ as shown in Figure 6(a). The highest magnitude of current (red) is related to the corresponding element of radiation.

Group Delay is an important factor in communication systems especially ultra-wideband for example medical applications systems, security systems and satellite communication systems which are used for transmitting wideband data, because the distortion causes retraction of the $\mathrm{S} / \mathrm{N}$ ratio [16]-[22]. Flat and consistent GD with frequency is important. To avoid occurring of distortion it is recommended that the spectrum is treated in the same manner, over the proposed bandwidth of frequencies. When GD ripples are large they may cause 


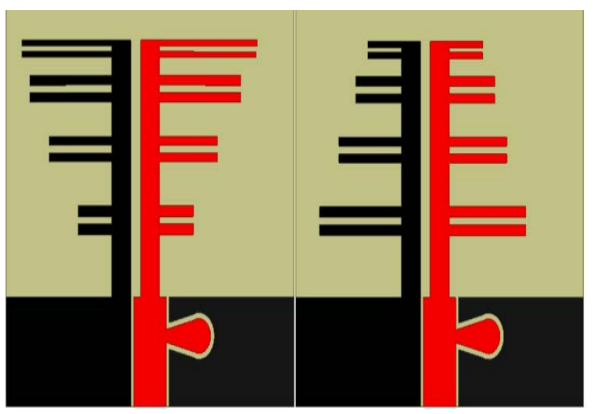

(a)

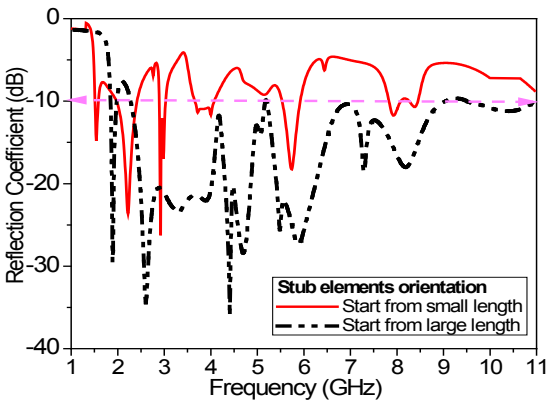

(b)

Figure 4. (a) Two different orientations of USLPDA and (b) the corresponding reflection coefficient $\left|S_{11}\right|$.

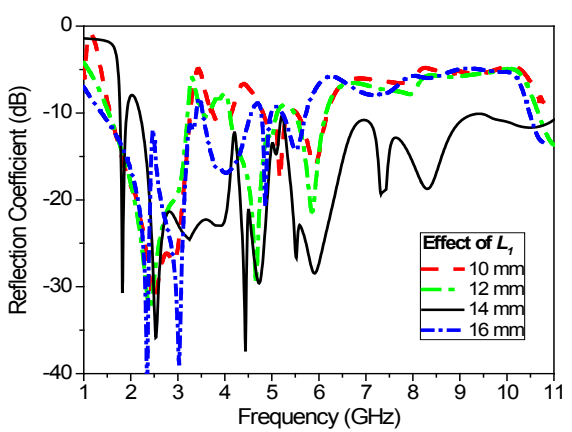

(a)

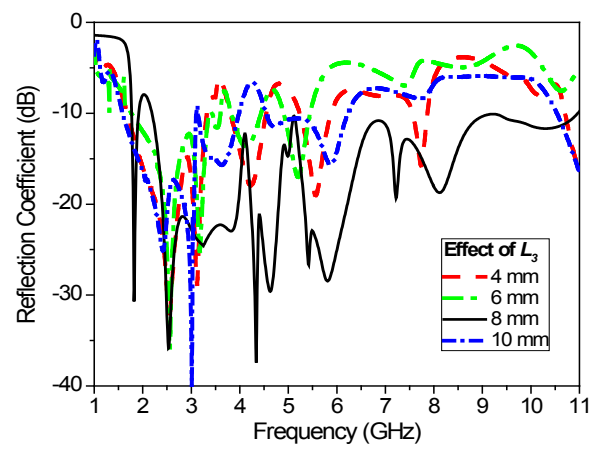

(c)

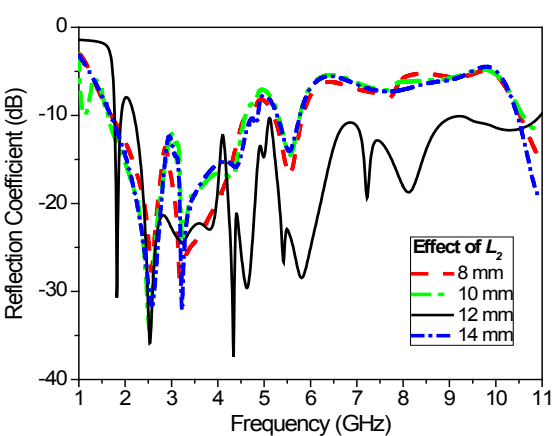

(b)

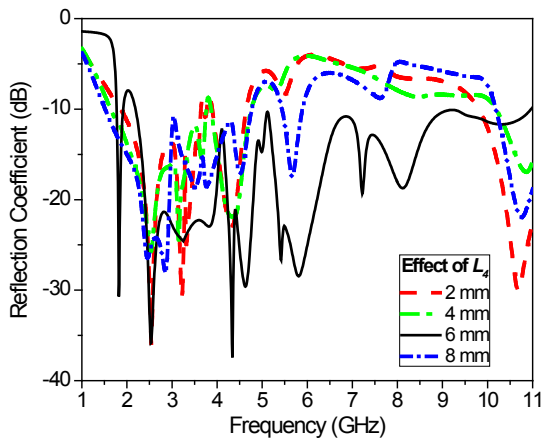

(d)

Figure 5. (a) to (d) Simulated S-parameters of proposed LPDA with varies arms $L_{1}, L_{2}, L_{3}$ and $L_{\phi}$ respectively.

Table 2. Dimensions of the proposed antenna (dimensions in $\mathrm{mm}$ ).

\begin{tabular}{cccccccccc}
\hline $\boldsymbol{L}_{\text {sub }}$ & $\boldsymbol{L}_{\boldsymbol{g}}$ & $\boldsymbol{W}_{\text {sub }}$ & $\boldsymbol{W}_{\boldsymbol{g}}$ & $\boldsymbol{W}_{\boldsymbol{1}}$ & $\boldsymbol{W}_{\mathbf{2}}$ & $\boldsymbol{W}_{\mathbf{3}}$ & $\boldsymbol{S}$ & $\boldsymbol{g}$ & $\boldsymbol{W}_{\boldsymbol{4}}$ \\
\hline 50 & 13.5 & 50 & 24 & 15.3 & 11.7 & 8.5 & 0.9 & 0.6 & 6 \\
$\boldsymbol{L}_{\text {sep }}$ & $\boldsymbol{L}_{4}$ & $\boldsymbol{L}_{\text {feed }}$ & $\boldsymbol{L}_{3}$ & $\boldsymbol{L}_{\boldsymbol{1}}$ & $\boldsymbol{L}_{2}$ & $\boldsymbol{W}_{\boldsymbol{f}}$ & $\boldsymbol{K}$ & $\boldsymbol{P}$ & $\boldsymbol{d}$ \\
7.6 & 2.1 & 45 & 2.8 & 3.6 & 3 & 6 & 8.5 & 4.5 & 1000 \\
\hline
\end{tabular}

unsatisfactory distortion in the signal of a transmitting radio system. So, in radio system design there is usually a specification for how much a GD that may be accepted. In nonlinear systems nonlinear distortion happens since the magnitude of 


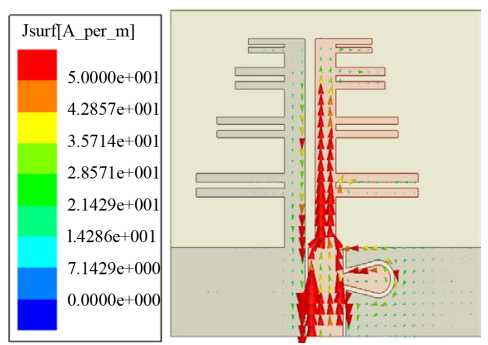

(a)

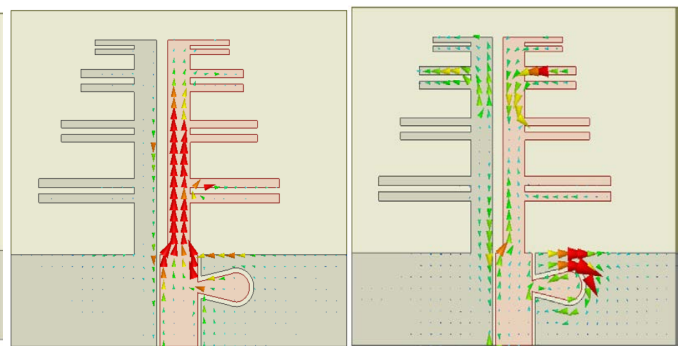

(b) (c)

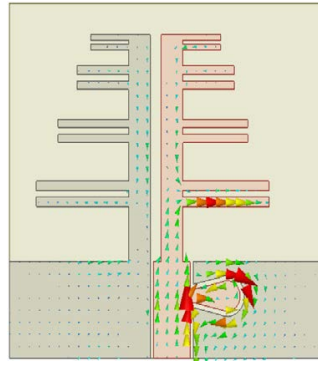

(d)

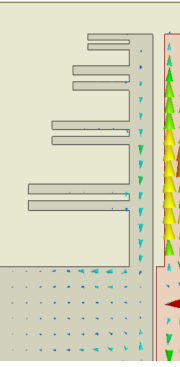

(e)

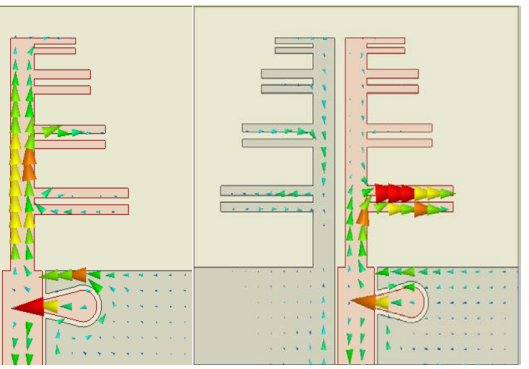

(f)

Figure 6. From (a) to (f) surface current densities for the USLPDA at 1.85, 2.45, 3.5, 5.5, 7.5 and $10 \mathrm{GHz}$, respectively.

frequency response is not constant and the phase of frequency response is nonlinear. By using GD the phase distortion could be measured, the phase characteristics must have a linear slope so that the ratio is constant for all frequencies and this represents a constant GD [21]. To measure the GD between two antennas with spacing $d=1 \mathrm{~m}$, the usual practice is to derive $\mathrm{Q} / \omega$ from $\left|\mathrm{S}_{21}\right|$ phase. However, it is desirable the same antenna be used for transition and receiving antenna. High GD variations, due to the steep phase shift over frequency, may cause unsatisfactory distortion in the signal. Figure 7 illustrates the simulated $\mathrm{GD}$, and it can be noticed that the average group delay is about $1.5 \times 10^{-9}$ second.

\section{Implementation and Measured Results}

Prototype of the proposed antenna is fabricated on FR4 substrate by using photolithographic technique, as shown in Figure 8 and performance parameters are measured. The simulated and measured input reflection coefficient of the antennas is in very good agreement, as shown in Figure 8(b). Impedance $-10 \mathrm{~dB}$ bandwidth of the proposed dipole antenna extended from $1.85 \mathrm{GHz}$ to $11 \mathrm{GHz}$ to cover most of wireless applications and FCC UWB regulation. The measurements were carried out by using a Rohde \& Schwarz ZVA67 vector network analyzer operating from $50 \mathrm{MHz}$ to $67 \mathrm{GHz}$. The comparisons between measured and simulated results of antenna gain and radiation efficiency are also studied as shown in Figure 9. The USLPDA antenna achieves simulated average gain $5.5 \mathrm{dBi}$ and the peak realized gain around $6.5 \mathrm{dBi}$ at $2.7 \mathrm{GHz}$ as shown in Figure 9(a). The measured results show very good agreement with simulated results and about $\pm 3 \mathrm{dBi}$ difference on average over the operating band. Wheeler 


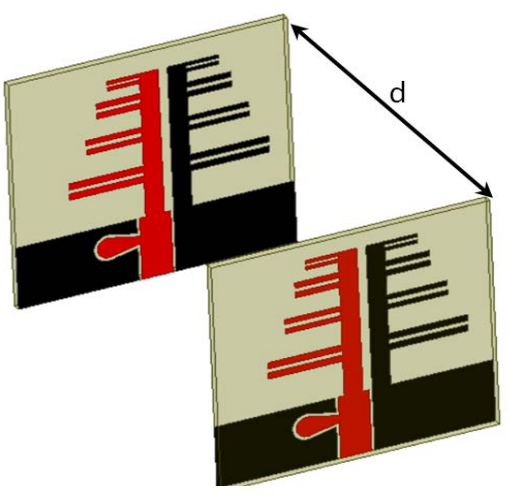

(a)

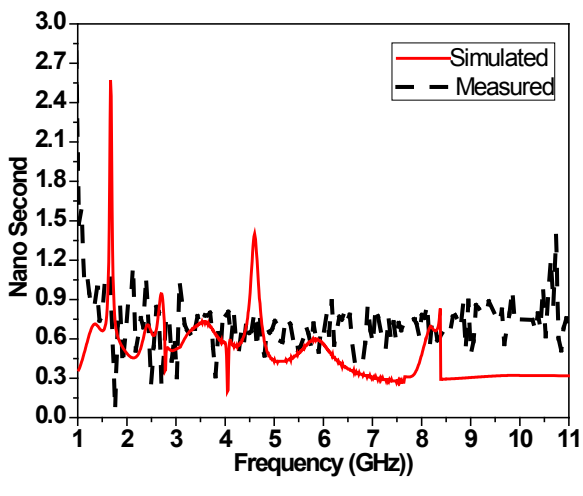

(b)

Figure 7. (a) GD Simulated structures and (b) comparison between measured and simulated GD of USLPDA.

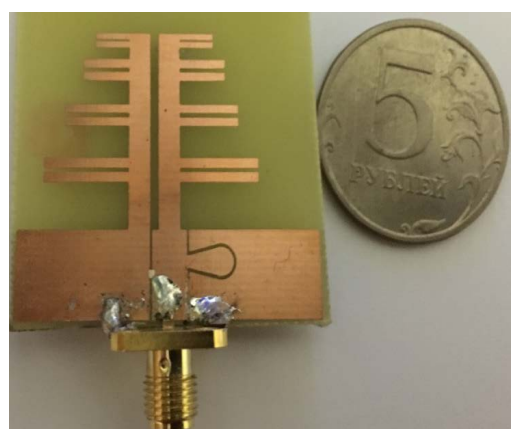

(a)

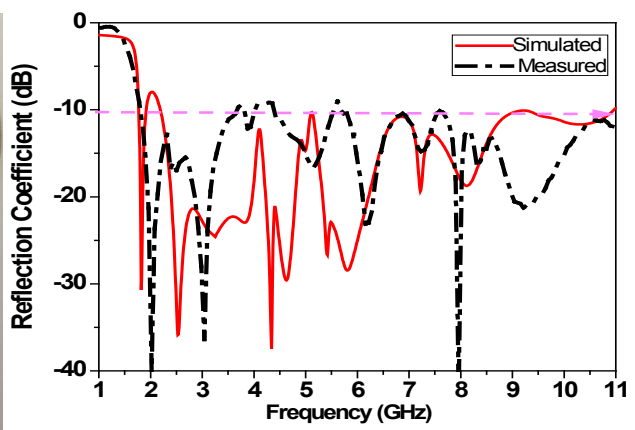

(b)

Figure 8. (a) Fabricated USLPDA antenna and (b) $\left|S_{11}\right|$ comparison between simulated and measured results.

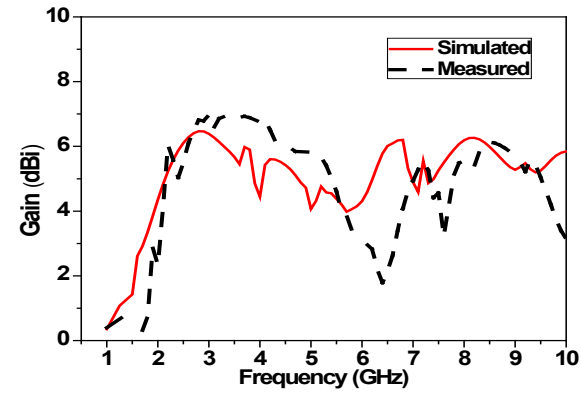

(a)

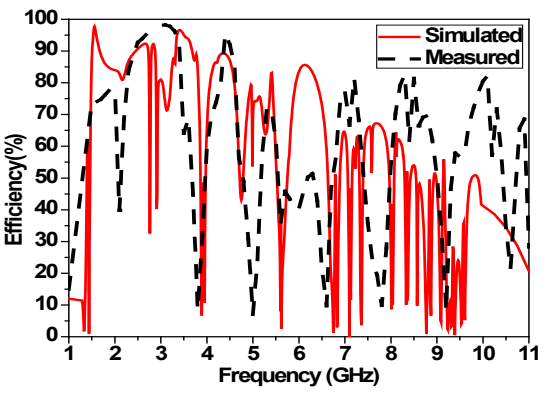

(b)

Figure 9. Comparison between simulated and measured results (a) gain and (b) radiation efficiency of USLPDA.

cap method [23] [24] can be used to calculate so that the antenna radiation efficiency was simulated for the proposed antenna by using. The average radiation efficiency is around $70 \%$ over the operating bands as shown in Figure $9(\mathrm{~b})$. Then the measured result of the radiation efficiency is done by using horn antenna to complete the proposed antenna radiation efficiency measurement as shown in Figure 9(b). Simulation and measured results for the two dimensional radiation patterns of two main planes (XZ and XY) are depicted in Table 3 at 
Table 3. Simulated and measured results of the proposed antenna radiation patterns in both XY and XZ planes at different frequencies. $1.85 \mathrm{GHz}, 2.45 \mathrm{GHz}, 3.5 \mathrm{GHz}, 5.5 \mathrm{GHz}$ and $7.5 \mathrm{GHz}$.

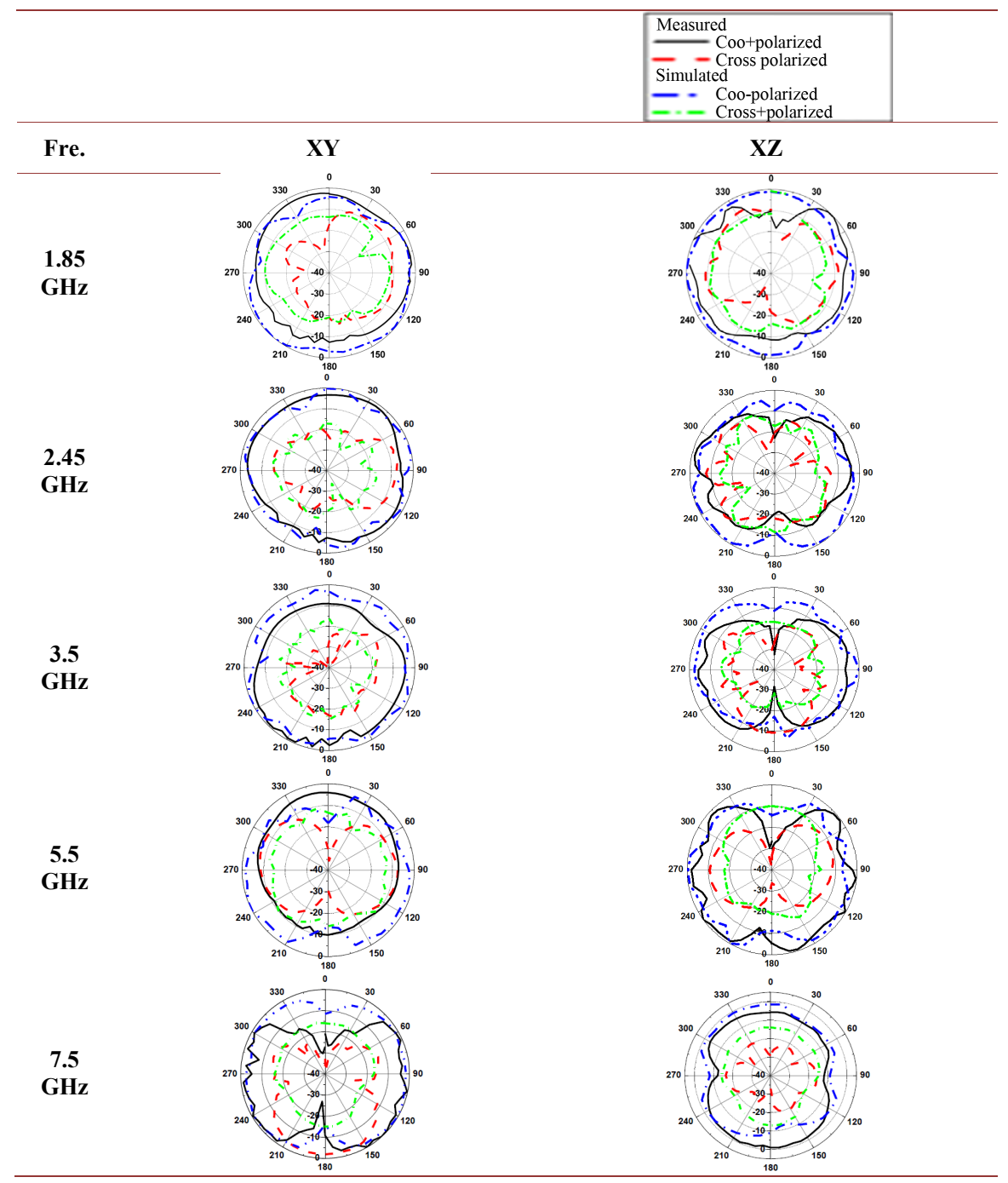

different resonant frequencies $1.85 \mathrm{GHz}, 2.45 \mathrm{GHz}, 3.5 \mathrm{GHz}, 5.5 \mathrm{GHz}$, and 7.5 $\mathrm{GHz}$, respectively. In the proposed antenna, the radiator and the ground plane are contributing to radiation. Omnidirectional radiation pattern is an important requirement for UWB applications. At lower frequencies of operation, the pattern resembles a conventional dipole antenna, but at higher end of the UWB spectrum some ripples are observed which are attributed to higher order modes. Some discrepancies are observed at higher frequency band spectrum which arises due to measurement setup. The simulated and measured results suggest that the proposed antenna shows satisfactory omnidirectional radiation characteristics throughout the UWB band.

\section{Conclusion}

A new ultra-wideband antenna consists of $U$ shaped log-periodic dipole antenna 
(USLPDA) has been proposed in this paper. The dipole is cascaded with four-U shaped elements to create an ultra-wideband extended from $1.85 \mathrm{GHz}$ to 11 $\mathrm{GHz}$. The proposed technique not only results in miniaturization of the antenna but also provides very stable radiation patterns throughout the whole frequency band. The proposed antenna can be easily fabricated on any commercially available substrates using the present design guidelines. This antenna has an average gain of $5.5 \mathrm{dBi}$ and $70 \%$ average radiation efficiency over the operating resonant frequencies. These features make the proposed antenna suitable for different wireless communication systems as well as UWB applications.

\section{Acknowledgements}

This work is funded by the National Telecom. Regulatory Authority (NTRA), Ministry of Communications and Information Technology (MCIT), Egypt through a contract with Electronics Research Institute.

\section{References}

[1] Yang, G.M. (2013) A Compact Microstrip Ultra-Wideband (UWB) Antenna for VHF/UHF Band Applications. IEEE AP-S, Orlando, FL, USA. https://doi.org/10.1109/APS.2013.6710666

[2] Federal Communication Commission (2002) First Report and Order-Revision of Part 15 of the Commission's Rules Regarding Ultra-Wideband Transmission System. FCC 0248.

[3] Elsheakh, D.N. and Abdallah, E.A. (2014) Compact Shape of Vivaldi Antenna for Water Detection by Using Ground Penetrating Radar (GPR). Microwave and Optical Technology Letters, 56. https://doi.org/10.1002/mop.28451

[4] Wang, C.J., Li, S.C., Sun, T.L. and Lin, C.M. (2013) A Wideband Stepped-Impedance Open-Slot Antenna with End-Fire Directional Radiation Characteristics. AEÜ - International Journal of Electronics and Communications, 67, 175-181. https://doi.org/10.1016/j.aeue.2012.07.008

[5] Dai, X.-W., Zhou, X.-Y. and Luo, G.-Q. (2017) Wideband Directional Antenna System with Different Polarizations for Wireless Communication System. AEÜ - International Journal of Electronics and Communications, 75, 119-123.

[6] Shameena, V.A., Mridula, S., Pradeep, A., Jacob, S., Lindo, A.O. and Mohanan, P. (2012) A Compact CPW Fed Slot Antenna for Ultra Wide Band Applications. International Journal of Electronics and Communication (AEU), 66, 189-194.

[7] Mazhar, W., Klymyshyn, D. and Qureshi, A. (2017) Log Periodic Slot Loaded Circular Vivaldi Antenna for 5-40 GHz UWB Application. Microwave and Optical Technology Letters, 59, 159-163. https://doi.org/10.1002/mop.30252

[8] Elsheakh, D.N. and Abdallah, E.A. (2014) Compact Multi and Compact Printed Log-Periodic Dipole Antenna for Terrestrial Digital Video Broadcast (DVB-T) Application. Microwave and Optical Technology Letters, 56, 1002-1007. https://doi.org/10.1002/mop.28249

[9] Zhang, F., Fang, G.-Y., Ji, Y.C., Ju, H.-J. and Shao, J-J. (2011) A Novel Compact Double Exponentially Tapered Slot Antenna (DETSA) for GPR Applications. IEEE Antennas and Wireless Propagation Letters, 10, 195-198.

[10] Lin, S., Luan, S., Wang, Y.D., Luo, X., Han, X., Zhang, X.Q., Tian, Y. and Zhang, 
X.Y. (2011) A Printed Log Periodic Tree Dipole Antenna (PLPTDA). Progress in Electromagnetics Research M, 21, 19-32.

[11] Wu, J., Zhao, Z., Nie, Z. and Liu, Q.H. (2014) A Printed UWB Vivaldi Antenna Using Stepped Connection Structure Between Slot Line and Tapered Patches. IEEE Antennas and Wireless Propagation Letters, 13, 698-701.

[12] Yu, C., Hong, W., Chiu, L., Zhai, G., Yu, C., Qin, W. and Kuai, Z. (2011) Ultrawideband Printed Log-Periodic Dipole Antenna with Multiple Notched Bands. IEEE Transactions on Antennas and Propagation, 59, 725-732.

[13] Fei, P., Jiao, Y.-C., Hu, W. and Zhang, F.-S. (2011) A Miniaturized Antipodal Vivaldi Antenna with Improved Radiation Characteristics. IEEE Antennas and Wireless Propagation Letters, 10, 127-130.

[14] Siddiqui, J.Y., Antar, Y.M.M., Freundorfer, A.P., Smith, E.C., Morin, G.A. and Thayaparan, T. (2011) Design of an Ultrawideband Antipodal Tapered Slot Antenna Using Elliptical Strip Conductors. IEEE Antennas and Wireless Propagation Letters, 10, 251-254.

[15] Casula, G., Maxia, P., Mazzarella, G. and Montisci, G. (2013) Design of a Printed Log Periodic Dipole Array for Ultra-Wideband Applications. Progress in Electromagnetics Research C, 38, 15-26.

[16] Rajendran, J. and ShanmughaSundaram, G.A. (2014) Design and Evaluation of Printed Log Periodic Dipole Antenna for an L Band Electrically Steerable Array System. International Conference on Computational Systems and Communications, Trivandrum, 17-18 December 2014, 311-316.

[17] Casula, G.A. (2013) A Printed LPDA Fed by a Coplanar Waveguide for Broadband Applications. IEEE Antennas and Wireless Propagation Letters, 12, 1232-1235. https://doi.org/10.1109/LAWP.2013.2283088

[18] Veeramani, A. and Dwivedi, R. (2015) Comparative Study of Coplanar Waveguide Feed and Microstrip Feed for Log Periodic Antennas. International Conference on Signal Processing and Integrated Networks, New Delhi, 19-20 February 2015, 10-14.

[19] Bozdag, G. and Kustepeli, A. (2016) Subsectional Tapered Fed Printed LPDA Antenna with a Feeding Point Patches. IEEE Antennas and Wireless Propagation Letters, 15, 437-440. https://doi.org/10.1109/LAWP.2015.2451395

[20] Haraz, O.M., Alshebeili, S.A. and Sebak, A.R. (2014) Low-Cost High Gain Printed Log-Periodic Dipole Array Antenna with Dielectric Lenses for V-Band Applications. IET Microwaves, Antennas \& Propagation, 9, 541-552.

[21] Bahramzy, P. and Pedersen, G.F. (2013) Group Delay of High Q Antenna. Antennas and Propagation Society International Symposium, Orlando, 7-13 July 2013. https://doi.org/10.1109/APS.2013.6711264

[22] Mohanan, D. and Satheesh Kumar, K.G. (2015) A Wideband Printed LPDA for Surveillance Applications. International Journal of Innovative Research in Computer and Communication Engineering, 1, 735-741.

[23] Johnston, R.H. and Mc Rory, J.G. (1998) An Improved Small Antenna Radiation Efficiency Measurement Method. IEEEAP-Magazine, 40, 40-48.

[24] Pozar, D.M. and Kaufman, B. (1988) Comparison of Three Methods for the Measurement of Printed Antenna Efficiency. IEEE Transactions on Antennas and Propagation, 36, 136-139. 